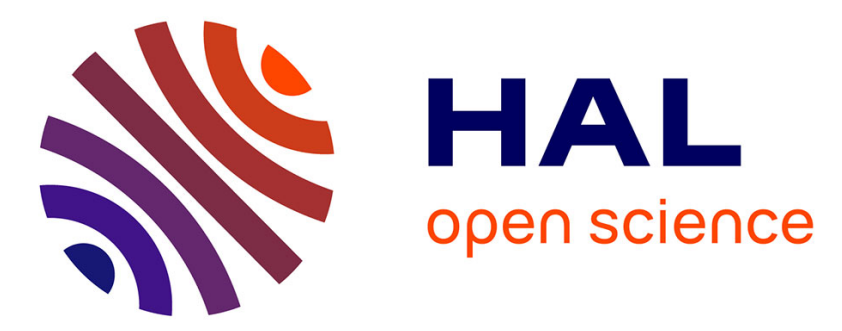

\title{
Consignment Stock Inventory Policy: Methodological Framework and Model
}

\author{
Daria Battini, Andrea Grassi, Alessandro Persona, Fabio Sgarbossa
}

\section{To cite this version:}

Daria Battini, Andrea Grassi, Alessandro Persona, Fabio Sgarbossa. Consignment Stock Inventory Policy: Methodological Framework and Model. International Journal of Production Research, 2010, 48 (07), pp.2055-2079. 10.1080/00207540802570669 . hal-00565119

\section{HAL Id: hal-00565119 https://hal.science/hal-00565119}

Submitted on 11 Feb 2011

HAL is a multi-disciplinary open access archive for the deposit and dissemination of scientific research documents, whether they are published or not. The documents may come from teaching and research institutions in France or abroad, or from public or private research centers.
L'archive ouverte pluridisciplinaire HAL, est destinée au dépôt et à la diffusion de documents scientifiques de niveau recherche, publiés ou non, émanant des établissements d'enseignement et de recherche français ou étrangers, des laboratoires publics ou privés. 


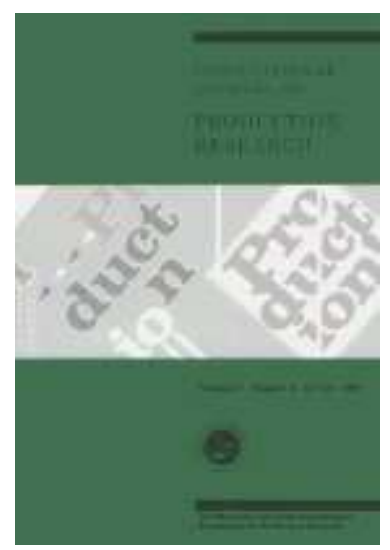

Consignment Stock Inventory Policy: Methodological Framework and Model

\begin{tabular}{|r|l|}
\hline Journal: & International Journal of Production Research \\
\hline Manuscript ID: & TPRS-2008-IJPR-0272.R1 \\
\hline Manuscript Type: & Original Manuscript \\
\hline Complete List of Authors: & $\begin{array}{l}\text { battini, daria; University of Padova, Dpt. Manufacturing \& Technology } \\
\text { management } \\
\text { Grassi, Andrea; university of modena and reggio emilia, Dept. of Science and } \\
\text { Engineering Methods } \\
\text { Persona, Alessandro; University of Padova, Dpt. Manufacturing \& Technology } \\
\text { management } \\
\text { sgarbossa, fabio; university of padova, Dpt. Manufacturing \& Technology } \\
\text { management }\end{array}$ \\
\hline Keywords: & $\begin{array}{l}\text { SUPPLY CHAIN MANAGEMENT, STOCHASTIC MODELS, PROCESS MODELLING, } \\
\text { OUTSOURCING }\end{array}$ \\
\hline Keywords (user): & \begin{tabular}{l} 
Consignment Stock, Framework \\
\hline
\end{tabular} \\
\hline \multicolumn{2}{|c}{}
\end{tabular}

\section{S) ScholaroNE \\ Manuscript Central}




\begin{abstract}
Consignment Stock (CS) is an innovative approach to supply and stock management, based on a strong and continuous collaboration between vendor and buyer to create a "win-win" situation, where both partners have equal gains. An analytic formulation of CS policy with obsolescence has been proposed in Persona et al. (2005).

This article considers new critical factors (present in several industrial environments) providing a logical extension of the above mentioned study. The proposed methodology addresses, in particular, the design of a new stock in an industrial environment with demand variability, stock-out risk and limited warehouses space.

The analytical model presented demonstrates that a traditional stock policy, such as the Economic Order Quantity approach is always more expensive than the Consignment Stock approach. In addition, the benefits of the CS policy to the supply chain are consistently high including when applied to realities with high demand variation and space limitations.
\end{abstract}




\title{
Consignment Stock Inventory Policy: Methodological Framework and Model
}

\begin{abstract}
Consignment Stock (CS) is an innovative approach to supply and stock management, based on a strong and continuous collaboration between vendor and buyer to create a "win-win" situation, where both partners have equal gains. An analytic formulation of CS policy with obsolescence has been proposed in Persona et al. (2005).

This article considers new critical factors (present in several industrial environments) providing a logical extension of the above mentioned study. The proposed methodology addresses, in particular, the design of a new stock in an industrial environment with demand variability, stock-out risk and limited warehouses space.

The analytical model presented in this study demonstrates that a traditional stock policy, such as the Economic Order Quantity method is always more expensive than the Consignment Stock approach. In addition, the benefits of the CS policy to the supply chain are consistently high including when applied to realities with high demand variation and space limitations.
\end{abstract}




\section{Introduction}

In a traditional supply process, both partners, buyer and vendor, incur financial disbursement, whether due to stocking or holding costs.

A Consignment Stock Policy_(from here on referred as CS policy) leads to a change in the costs structure for both the partners (Valentini and Zavanella, 2003). For a better understanding of the industrial scenario analyzed, few clarifications are necessary. The holding unit cost, $h$, is calculated as the sum of two principal components: the financial component, $h_{\text {fin }}$, and the stock component, $h_{s t o c}$. The first refers to the opportunity costs of the company when it invests financial resources in the production of a product. The second, refers to the warehousing costs of the item (stocking, handling, insurance, etc.). In a CS policy, the buyer incurs in stocking costs, since the materials are located in its plant, but it doesn't sustain financing cost, since the item is purchased only when needed. In fact, since the item is formally purchased upon demand, the vendor sustains the financial costs of the capital immobilized until that moment. The buyer can perceive a reduction in holding cost, which is only equal to $h_{\text {stoc }}$, rather than to $h_{\text {stoc }}+h_{\text {fin }}$ (Valentini and Zavanella, 2003). Moreover, Valentini and Zavanella (2003) underline that order emission costs are also eliminated.

The vendor also receives a number of advantages. First of all, the average stock is reduced leaving more available space for stocking new items. Moreover, the vendor increases his production management flexibility since he is no longer constricted by consecutive close orders. For these reasons, a CS policy aims to reduce management and logistic complexity of the stocks and to ensure at the same time a constant availability of materials in order to eliminate stock-out risks (Table 1).

\section{[PLACE HERE TABLE 1]}

From the examples collected by the authors, consumer items, such as metallic and plastic fasteners, small parts, tools, packaging parts and personal protection equipments (PPE) are some of the items for which a CS policy guarantees the biggest benefits. $\underline{\text { In }}$ light of these considerations, this work analyses and quantifies all the benefits arising from the establishment of a CS policy in a traditional environment, managed by the well known Economic Order Quantity method (EOQ), which is characterised by a reorder point and a fixed order size. This article focuses especially on items characterized by high annual consumption (in number of pieces), low dimension, 
variable demand and risk of obsolescence, and integrates and completes existing studies by Braglia and Zavanella (2003) and Persona et al. (2005), touching upon some additional aspects that were not previously considered, such as:

1) the development of an integrated framework to assist the analyst when addressing the problem of switching stock management policy from traditional to CS.

2) an extension of the model developed by Persona et al. (2005), which includes safety stocks, stock-out risk and restricted space availability, issues theat were never addressed in previous studies.

3) a demonstration, for the first time, that Consignment Stock policy is always convenient when compared with the well known EOQ policy for standard components, like consumables materials.

The analytical model developed to support the framework allows to calculate the optimal delivery quantity which is the quantity that minimizes total annual supply chain management costs.

Section 2 presents a state of the art classification and overview on this topic. The new methodological framework is presented and discussed in section 3 , while in section 4 the analytical model is developed to support the framework application. Finally, a numerical application of the model is proposed in section 5 where CS policy is compared to a traditional policy, as a prelude to the article's conclusions.

\section{State of the art}

International literature on $\mathrm{CS}$ is still very limited. Table 2 summarizes the main references and classifies them according to the authors' assumptions, such as: market demand modelling, lead time quantification (including production lead time, procurement lead time, transport lead time, etc.), risk of obsolescence of materials in stock (finite or infinite life cycle), type of logistics system considered.

The analytical model for the evaluation of CS policy annual costs developed by Braglia and Zavanella (2003), refers to the problem of a single vendor and single buyer production situation: the objective of the study is to minimize the total system cost function, that is the sum of buyer and vendor costs. The model considers a constant and fixed product demand during the year, infinite life cycle of products and a fixed delivery quantity $q$. The same authors highlight some possible inefficiencies of the model such as an increase in inventory levels on buyer's side, even if they are shortterm. A possible solution to prevent this inconvenience is to postpone the last delivery. 


\section{[PLACE HERE TABLE 2]}

Persona et al. (2005) propose an interesting contribution that focuses on the materials obsolescence topic, developing an analytical model, which is an extension of the previous one. Such model could help evaluate obsolescence impact on the supply chain. In traditional procurement policies the risk of obsolescence is completely sustained by the buyer, since the stock in his warehouses is his property. In a CS approach, the risk of obsolescence is a critical factor, because the cost associated with it shared costs between buyer and vendor, who is the owner of the materials in consignment stock. The delivery quantity is therefore a critical variable and must be contained. An example for reducing costs by the CS policy application is provided by Piplani and Viswanathan (2003): the authors analyse a single-vendor and multi-buyer system in which the vendor maintains a SOI (Supplier Owned Inventory) accord with only one of his buyers ("the SOI buyer") and the annual costs sustained for managing other buyers are not considered. The results underline that in all combinations the total supply chain cost after the adoption of the SOI policy is less or at least equal to the corresponding traditional approach. Thus, the SOI strategy is defined by the authors as profitable for the supply chain as a whole, however, the vendor does not always obtain direct benefits. Hung et al. (2003) describe the implementation of the Consignment Stock policy at the "Consumer Electronics Division" of Philips (Taiwan) with the objective to reduce the material handling costs and the space occupied in the warehouse, integrating vendor and client to improve the information and communication level between partners. The authors develop an empirical method to define the minimum stock level 's', equal to an appropriate safety stock quantity, introducing a "fluctuation index", calculated as the ratio between the standard deviation in demand and the forecasted 
consumption rate. This article highlights a topic not yet touched by other authors: the quantification of the strategic parameter 's', based upon the following critical considerations of the researches reported in table 2:

1) The analysis of a single-vendor and single-buyer system, performed by the majority of the authors results in great simplification of the modern industrial reality: the necessity of future studies to address a systematic approach which considers a single-vendor and multi-buyer system type is hence evident. In this system a number of buyers can start a CS policy agreement with the same vendor, as happens in today's industrial reality.

2) From the examples presented above, CS shows to be a valid stock management policy, especially in the most instable environments with demand variability. However, a methodological framework to guide the implementation of this approach in traditional contexts has not yet been developed and a complete analytical model able to consider all critical factors (obsolescence, stock out risk and finite warehouse capacity) has not been presented in literature.

3) The most influential factors on the Consignment Stock implementation process are demand variability and finite life cycle of items (risk of obsolescence). However, procurement lead time variability should have been considered in some particular cases.

This paper addresses considerations 2) and 3) developing a new integrated framework for the CS implementation in presence of demand variability, risk of obsolescence and space limitations in the buyer's warehouse.

\section{Methodological framework}

As previously mentioned, the work presented develops a methodological framework able to address all the problems emerging when a project for the implementation of CS policy is going to be addressed in actual industrial situations, and offers an analytical model to calculate optimal inventory levels.

Several factors have been included to make the framework as near as possible to actual industrial situations.

Figure 1 shows the proposed framework. Logistics and manufacturing constraints typical of actual industrial systems constitute the base for the model, followed by the 10 phases of the framework. 
During the implementation of the project, it is necessary to accomplish each task independently from the partners' constraints, which should be individually addressed by both partners. Effective communication from the beginning of the partnership is of the outmost importance to reduce start-up times and inception delays. A CS implementation project should be based on a concurrent engineering paradigm, to ensure that the different activities, developed during the execution of the project, will be carried out by a cross-functional buyer-vendor group, with a continuous reciprocal agreement to prevent any delay in implementation time. Only with an integrated approach the partners will realize annual savings and effective implementation of this policy, without occurring in high start-up costs.

Regardless of who initiates the policy change, whether the vendor proposes the CS policy to the buyer or the buyer suggests a new policy to the vendor, choosing the right partner is crucial for the success of the experiment. From the buyer's point of view, the potential vendors should be those supplying critical components in volumes, value and significance for the final product (Valentini and Zavanella, 2003), those who posses a strong technological know-how and those whose business approach is oriented towards change, collaboration, information sharing, and to Total Quality Management (TQM). On the other hand, from the supplier's point of view, the potential buyers are certainly those able to guarantee a high annual turnover, and those who are willing to reserve sufficient space for stocking items and to tackle the standardisation of their components.

\section{[PLACE HERE FIGURE 1]}

The second step in the implementation of the CS policy consists of selecting the components suitable for such a management policy, which must be jointly carried out by both partners. Often, only a part of the components supplied by a specific vendor are suitable for CS management policy. Table 3, addresses some critical aspects that need to be taken into account and carefully measured for the success of the model.

The most suitable components for a CS agreement are generally the ones characterised by a high consumption (Valentini and Zavanella, 2003), since they can be supplied by open orders, as emphasized by the SOI theory. Since stocking costs must be contained, components and materials requiring particular stocking equipment or stocking environmental condition have to be excluded. In particular, since stocking space is 
limited and holding cost increases with size, the item size is a determining factor for the success of the trial. Hence, the buyer obtains maximum advantage if the CS policy manages components with a reduced size but high value, because the financial burden of the holding cost is carried by the vendor (Valentini and Zavanella, 2003). In general, adopting a CS policy with easy to handle components, facilitates supply and replenishment, offering a good starting point.

Another important factor to take into consideration is the expected lifetime of the component, or, in other words, its replaceability ratio or obsolescence. This element is dependent on four different elements: perishability (shelf life), replacement due to internal causes (modifications or replacement of the final product), replacement due to external causes (updates or new versions proposed by the supplier), perishing due to environmental causes (Persona et al., 2005).

\section{[PLACE HERE TABLE 3]}

In addition, components standardisation and data alignment between vendor and buyer (codes, dimensions, reference regulations, etc.), are of great importance in CS implementation projects, in spite of the timeliness of the task and the stress the operation puts on the resources. All future engineering choices and marketing decisions depend on an effective reduction in the number of items to manage. According to Koudate and Suzue (1992), applying the Variety Reduction Program guidelines to and inventory, might reduce the number of managed items by $35 \%$, with considerable savings. In fact, annual service costs borne by the buyer and agreed with the supplier in the contract drafting stage, are directly proportional to the number of items managed and to the number of locations assigned in the warehouse.

Effective data exchange is paramount for the success of the project, to track daily consumption. For a really efficient data exchange it is necessary to analyze who sends data and how frequently it is sent. A simple kanban system with a double box should be sufficient in many industrial environments, but in some instance a more sophisticated electronic system may sometimes be necessary.

Warehousing methods are to be analysed as well since the physical location of the stock, the centralization/decentralization rate of the stocks into the buyer's plant, the physical location in the plant, might affect supply warehousing and distribution methods. 
One of the main aspects in drafting a CS agreement is the definition of the lowest and highest stock levels, $s$ and $S$ respectively, for each item. In the definitions of such levels, from a negotiation between the vendor and the buyer, the partners tend to keep opposite positions. On one hand, the buyer generally tends to keep $s$ as high as possible, in order to reduce stock-out risk, and $S$ as low as possible to reduce assigned inventory space. On the other hand, the vendor will prefer a high $S$ level for greater operative flexibility and a low $s$ level to reduce holding costs (Abdel-Malek et al., 2002). Currently, scientific literature does not provide standard formulas for the calculation of $s$ and $S$ levels with the adoption of CS management policy.

It is practical to use the lowest inventory level $s$ as a minimal safety stock determined as a function of the maximum vendor reaction time (physiological and not null) in case of an overrunning under $s$, and the highest inventory level $S$ as a function of the maximum available inventory space at the buyer's plant. Often, both levels are expressed in weeks (or months) of consumption coverage. Once $s$ and $S$ levels are defined, the optimal shipment quantity $q$ is determined. Optimal shipment quantity is the quantity that allows to minimize the vendor-buyer total annual costs.

Different analytical linear models have been developed over the last year to asses the calculation of the best delivery quantity $q$, considering different input variables and working conditions: demand variability, obsolescence, lead time variability. The model developed to support this step of the framework is discussed in the next paragraph and allows three general conditions to be combined in a single model: demand variability presence, risk of obsolescence not null and space limitations at buyer's warehouse. The model developed allows calculation of the optimal delivery quantity $q$ and the forecasting of all costs involved per one year period in the whole system and for each partner. The methodological framework is finally concluded by the management costs forecasting for both partners involved, followed by the CS agreement preparation and the setting at zero of inventory levels at buyer's side.

\section{The analytical model}

The analytical model developed in this section considers a single-vendor and singlebuyer system, and compares a CS policy with a traditional supply management system. To determine the economic impact of a CS policy, it is assumed that the buyer switches from an Economic Order Quantity (EOQ) management (traditionally adopted for articles such as fasteners, metallic minutia, packaging, personal protective equipments, 
etc.), to a CS policy. The inventory level is constantly monitored and an order is placed each time the inventory reaches a predefined reorder point. Both models take into account logistic and manufacturing constraints on both vendor and buyer side, as reported in the framework of Figure 1, while for the sake of this experiment, total annual costs will be made up of the following cost components:

- Vendor's setup costs;

- Handling and warehousing costs of both partners, including safety stock contribution;

- Financial immobilization of inventories (borne by both of the actors in a traditional policy; only for the vendor in the case of CS policy);

- Stock-out costs (borne by both of the actors in a CS policy);

- Vendor's shipment costs;

- Obsolescence cost (borne by both of the actors in a CS policy);

- Storage res (borne by the vendor in a CS policy);

- Hiring costs of equipment needed for storing and distributing items (i.e. dispensers managed with personalised electronic badges).

\section{a) Analytical model for the traditional inventory management policy}

In an traditional inventory management policy, characterised by a reorder point and fixed order size, cost components are expressed as a function of the fixed reorder quantity, and the model will derive the order quantity which minimises total annual costs.

In such a traditional system, some of the strategic characteristics become fundamental and the following hypothesis need to be considered:

i) The system is managed by a fixed reorder point;

ii) The fixed reorder quantity $Q_{t}$ is such that total annual costs are minimised;

iii) Buyer's demand is stochastic and normally distributed according to a monthly average demand $D_{m}$ (units/month) and a standard deviation $\sigma$ (units/month);

iv) Item life, $T$, is limited (Persona et al., 2005);

v) Shipment costs are charged to the vendor, whereas warehouse refilling costs are borne by the buyer;

vi) The vendor does not incur obsolescence costs, since the buyer is committed to buy each order issued. Hence, obsolescence costs are borne solely by the buyer. 
vii) Only the buyer reserves a safety stock in his warehouse to protect himself from market demand fluctuations and from stock-out costs;

viii) Space limitations at the buyer's plant limit the maximum material quantity to be stored in the buyer's warehouse. The maximum quantity storable is equal to $S$ and it is calculated considering the available space at buyer's plant and material characteristics.

The following notations are adopted:

$A_{1} \quad$ vendor's setup cost (€/setup);

$A_{2} \quad$ buyer's order issue cost (including warehouse refilling cost) (€/order);

$O \quad$ vendor shipment cost, (€/shipment);

$D_{m} \quad$ buyer's monthly average demand, (units/month);

$\sigma \quad$ buyer's standard deviation in demand, (units/month);

$D \quad$ buyer's annual average demand, $D=D_{m} \cdot 12$ (units/year);

$i_{f} \quad$ vendor's annual interest rate $(\%)$;

$s_{f} \quad$ vendor's holding cost rate $(\%)$

$i_{c} \quad$ buyer's annual interest rate $(\%)$;

$s_{c} \quad$ buyer's holding cost rate $(\%)$

$L T_{f} \quad$ vendor's manufacturing lead time for the production and shipment of the optimal delivery quantity $q$, (months);

$L T_{c} \quad$ buyer's procurement lead time (months);

$w \quad$ number of annual cycles of the system, that is, the number of times the vendor produces the quantity $Q_{t}$;

$P \quad$ production rate of the vendor (units/year);

$c_{p} \quad$ production cost (€/unit);

$p \quad$ item price (€/unit);

$c_{m, c} \quad$ buyer's stock-out cost (€/unit);

$S \quad$ maximum inventory level allowed in the buyer's warehouse (units);

$T \quad$ item lifetime (years).

$Q_{t} \quad$ reorder quantity (units/order)

$s s_{c} \quad$ safety stocks at buyer's plant 
The objective of the model is to minimize the total system cost: $\min \left(C_{t o t}\right)$, which represents the sum of all the costs borne by vendor and buyer, subject to the following constraints:

1) $Q_{t} \geq 0$

2) Maximum_inventory_level $\leq S$

Inventory holding costs (subdivided in financing and stock component according to Valentini and Zavanella, 2003) are borne by both the vendor and the buyer, proportionally with time each item is kept in each respective warehouse.

Such costs are defined by the following expressions:

$h_{f i n, f}=i_{f} \cdot c_{p} \quad$ Vendor financial cost ( $€ /$ unit in stock)

$h_{s t o c, f}=s_{f} \cdot c_{p} \quad$ Vendor stocking cost $(€ /$ unit in stock $)$

$h_{f i n, c}=i_{c} \cdot p \quad$ Buyer financial cost $(€ /$ unit in stock $)$

$h_{s t o c, c}=s_{c} \cdot p \quad$ Buyer stocking cost $(€ /$ unit in stock $)$

Safety stocks maintained only at the buyer's plant are calculated according to the traditional formula:

$s S_{c}=k \cdot \sigma \cdot \sqrt{L T_{c}} \quad$ (units)

where:

$L T_{c}$ is the procurement lead time agreed with the supplier and is generally constant.

The costs borne by the sole vendor $(f)$ are expressed by means of the following formulae:

1. Setup costs:

$C_{s}^{f}=\frac{D}{Q_{t}} \cdot A_{1}$

2. Holding costs:

$C_{m}^{f}=\left(\frac{Q_{t}}{2}\right)\left(i_{f}+s_{f}\right)\left(c_{p} \frac{D}{P}\right)$

3. Shipment costs:

$C_{t r}^{f}=\frac{D}{Q_{t}} \cdot O$

The costs borne by the buyer $(c)$ are expressed with the following formulae:

1. Order emission costs: 
$C_{\text {ord }}^{c}=\frac{D}{Q_{t}} \cdot A_{2}$

2. Holding costs:

$C_{m}^{c}=\left(\frac{Q_{t}}{2}+s s_{c}\right)\left(i_{c}+s_{c}\right) p$

3. Stock-out costs (Vollman et al., 1997, Persona et al., 2007):

$C_{R S}^{c}=D_{p} \cdot c_{m, c}=D_{R S, c} \cdot w \cdot(1-L S) \cdot c_{m, c}$

Where:

$D_{p}$ is the annual sale loss,

$w$ is the total number of shipments to be carried out in a year,

$L S$ is the Service Level $=1$ - Probability of running out of stock. The Service Level is associated with area under the Gaussian curve therefore this will leads us the corresponding $\mathrm{Z}$ value for the normal table (Persona et al., 2007).

$R S$ are the number of stock-outs in a year,

$D_{R S}$ is the average value of unfulfilled demand when a stock-out occurs, i.e. when demand $D$ is greater than the maximum admissible level of stocks (the complete formula derived by normal distribution function is reported in Persona et al., 2007).

The following expression are used to compute the above quantities:

$D_{p}=D_{R S, c} \cdot R S=D_{R S, c} \cdot w \cdot(1-L S)$

$w=\frac{D}{Q_{t}}$

$R S=w \cdot(1-L S)$

4. Obsolescence costs:

$C_{o}^{c}=p \cdot \frac{\left(\frac{Q_{t}}{D_{m}}-L T_{c}\right) \cdot\left\{D_{m} L T_{c}+s s_{c}+\left(Q_{t}-\frac{Q_{t}-L T_{c} D_{m}}{2}\right)\right\}+L T_{c}\left(Q_{t}+s s_{c}+\frac{L T_{c} D_{m}}{2}\right)}{\frac{Q_{t}}{D_{m}}} \cdot \frac{1}{T}$

In formula (15) we express the problem considering a deterministic time-toobsolescence instance. The formula expresses the obsolescence cost as a weighted average of two different cases (as depicted in Figure 2): the amount of leftover stock in buyer's warehouse in case the obsolescence occurs before reaching the point of reorder (Case A in Figure 2) and the amount of leftover stock in buyer's warehouses in case the 
obsolescence occurs after reaching the reorder level (Case B in Figure 2). In this last case we must consider also the leftover stock of the quantity $Q_{t}$ already ordered to the supplier. The two quantities are weighted in base of the time-to-obsolescence length of both cases. Finally the obsolescence cost expressed in formula (15) has been divided for the item lifetime $\mathrm{T}$ (expressed in years).

\section{[PLACE HERE FIGURE 2]}

Finally, the whole system costs will be:

$C_{\text {tot }}=C_{s}^{f}+C_{t r}^{f}+C_{m}^{f}+C_{o r d}^{c}+C_{m}^{c}+C_{o}^{c}+C_{R S}^{c}$

\section{b) Analytical model for the consignment stock management policy}

When a consignment stock management policy is adopted, the cost structure undergoes some changes, and the supplier will bear some of the obsolescence, holding and refilling costs.

The model is based on the following hypothesis:

i) The fixed shipment quantity $q$ is such that total costs are minimized;

ii) The buyer's demand is distributed with an average monthly demand $D_{m}$ (units/month) and standard deviation $\sigma$ (units/month);

iii) Item life, $T$, is finite (Persona et al., 2005);

iv) Vendor and buyer lead time are known constants, and are expressed in months, coherently with the demand;

v) The buyer is no longer subjected to order issue costs (Valentini and Zavanella, 2003);

vi) The vendor delivers the order to the buyer as soon as each amount $q$ has been produced, carrying out a production batch $Q=q \cdot n$. (Braglia and Zavanella, 2003);

vii) Shipment and refilling costs are charged to the supplier;

viii) The procurement lead time experienced by the buyer when a stock-out occurs is reduced to the so-called "vendor's maximum reaction time". Hence, it is consistently lower than the lead time experienced in the traditional supply policy (this hypothesis is derived by the fact that in real situations the consideration of a null lead time is too hazardous); 
ix) The vendor and the buyer always maintain a safety stock at their plants;

x) The minimum inventory level $s$ is the safety stock computed as a function of the procurement lead time defined in (viii);

xi) The maximum inventory level in the buyer's plant cannot exceed the maximum agreed level $S$. This level is calculated as a function of the maximum available space in the buyer's plant as reported in the step 6 of the framework (Figure 1).

The following clarifications are necessary in order to fully understand the model:

$A_{1} \quad$ vendor's setup costs ( $€ /$ setup);

$O \quad$ vendor's shipment and refilling cost (€/shipment);

$D_{m} \quad$ buyer's average monthly demand (units/month);

$\sigma \quad$ buyer's standard deviation in demand (units/month);

$D$ annual demand, $D=D_{m} \cdot 12$ (units/year);

$i_{f} \quad$ vendor's annual interest rate (\%);

$s_{f} \quad$ vendor's holding cost rate (\%);

$i_{c} \quad$ buyer's annual interest rate (\%);

$s_{c} \quad$ buyer's holding cost rate (\%);

$n \quad$ number of shipments per batch;

$n^{*} \quad$ number of shipments in the last production batch, when obsolescence occurs;

$\bar{n} \quad$ number of shipments in the last consignment stock cycle, when obsolescence occurs;

$L T_{f} \quad$ time required by the vendor to produce the quantity $q$, (months);

$L T_{c} \quad$ vendor's maximum reaction time (months);

$w$ number of shipments executed in a year, that is, the number of times the vendor produces the quantity $q$ (shipments/year);

$P \quad$ vendor's production rate (units/year);

$c_{p} \quad$ vendor's item cost (€/unit);

$p \quad$ item price for the buyer (€/unit);

$c_{m, f} \quad$ vendor's stock-out cost per unit (€/unit);

$c_{m, c} \quad$ buyer's stock-out cost per unit (€/unit);

$S \quad$ maximum inventory level in buyer's plant (units); 
$s \quad$ minimum inventory level in buyer's plant (units);

$s s_{f} \quad$ safety stocks at supplier's plant

$s s_{c} \quad$ safety stocks at buyer's plant

$T \quad$ item lifetime (years);

$t^{*} \quad$ time between the begins of the last cycle and the occurrence of the obsolescence;

$\lfloor x\rfloor$ the lower integer of a variable $x$ if $x \geq 0$, otherwise 0 if $x<0$.

The variable of the model is $q$, representing the quantity sent by the vendor to the buyer in each shipment (units/shipment).

The objective of the model is to minimize the system total cost $\left(\min \left(C_{t o t}\right)\right)$, being the sum of the costs borne both by the vendor and the buyer, subject to the same previous constraints.

The financial component of the inventory holding costs at the buyer's plant are charged to the vendor, since he keeps the ownership of the items (Valentini and Zavanella, 2003), hence formula (3) becomes:

$h_{\text {fin }, c}=i_{c} \cdot p=0$

In case of a CS policy, the model assumes that demand variability perceived by both partners is equal to market demand variability, since the well known Bullwhip Effect, studied by Forrester under the hypothesis that an OP-EOQ reorder policy (Forrester, 1958) can be drastically reduced under a CS policy with only two echelons. In fact, the different perception of demand variability is reduced by shorter delivery lead time, by the increased reliability of information flow under the CS policy and by a better inventory coordination. Under this assumptions we can express vendor's and buyer's safety stocks using the analytical model formula, based on the supply lead time of component LT (Vollman et al. 1997 and Persona et al., 2007), as follows:

$$
\begin{array}{ll}
s s_{f}=k \cdot \sigma \cdot \sqrt{L T_{f}} & \text { (units) } \\
s s_{c}=k \cdot \sigma \cdot \sqrt{L T_{c}} & \text { (units) }
\end{array}
$$

where:

$L T_{f}=\frac{Q_{g}}{P}$

$L T c$ is constant and expressed according to viii) . 
The minimum inventory level $s$ in the buyer's warehouse is equal to the safety stock:

$s=s s_{c}=k \cdot \sigma \cdot \sqrt{L T_{c}}$

Moreover, since the item life is limited, we consider the following expression (Persona et al., 2005):

$t^{*}=T-\left\lfloor\frac{T D}{n q}\right\rfloor \frac{n q}{D}$

where $n q / D$ is the length of a CS cycle, and as a consequence $D / n q$ is the number of CS cycles in a year.

$n^{*}=n-\left\lfloor\frac{n q+\frac{q D}{P}-S-D t^{*}}{q}+1\right\rfloor$

where $\mathrm{qD} / \mathrm{P}$ is the inventory level at which the vendor starts the production of the batch $Q=n p$.

$\bar{n}=\min \left\{\left\lfloor\frac{t^{*} P}{q}\right\rfloor ; n\right\}$

We now define the costs for the vendor and the buyer.

Vendor's costs:

1. Setup costs:

$$
C_{s}^{f}=\frac{A_{1}}{T}\left\lfloor\frac{D T}{n q}+1\right\rfloor
$$

2. Holding cost:

a. inventory located in vendor's plant (Persona et al, 2005):

$$
\begin{aligned}
& C_{m, 1}^{f}=\frac{\left(h_{f i n, f}+h_{s t o c, f}\right)}{T}\left[\frac{\left(q+s s_{f}\right)-s s_{f}}{2}\left(\frac{n q}{P}\left\lfloor\frac{T D}{n q}\right\rfloor+\frac{n^{*} q}{P}\right)\right]+\frac{\left(h_{f i n, f}+h_{s t o c, f}\right)}{T}\left[s s_{f}\left(\left\lfloor\frac{T D}{n q}\right\rfloor \frac{n q}{D}+t^{*}\right)\right] \\
& \left.=\frac{\left(h_{f i n, f}+h_{s t o c, f}\right)}{T}\left[\frac{q}{2}\left(\frac{n q}{P} \mid \frac{T D}{n q}\right\rfloor+\frac{n^{*} q}{P}\right)\right]+\frac{\left(h_{f i n, f}+h_{s t o c, f}\right)}{T}\left[s s_{f}\left(\left\lfloor\frac{T D}{n q}\right\rfloor \frac{n q}{D}+t^{*}\right)\right]
\end{aligned}
$$

b. inventory located in buyer's plant (Persona et al., 2005): 


$$
\begin{aligned}
& C_{m, 2}^{f}=\frac{h_{f i n, f}}{T}\left\{\frac{S-s s_{c}}{2}\left|\frac{T D}{n q}\right| \frac{n q}{D}+\frac{1}{2}\left(\frac{q D}{P}+(\bar{n}-1) q\left(1-\frac{D}{P}\right)\right) \frac{q \bar{n}}{P}+\frac{1}{2}\left[2\left(\left(\overline{n q}-(\bar{n}-1) q \frac{D}{P}\right)+s s_{c}\right)-D\left(t^{*}-n \frac{q}{P}\right)\right]\left(t^{*}-n \frac{q}{P}\right)\right\}+ \\
& +\frac{h_{f i n, f}}{T}\left[s s_{c} \cdot\left\lfloor\frac{T D}{n q} \mid \frac{n q}{D}+s s_{c} \cdot \frac{q n}{P}\right]=\right. \\
& =\frac{h_{f i n, f}}{T}\left\{\frac{S}{2}\left|\frac{T D}{n q}\right| \frac{n q}{D}+\frac{1}{2}\left(\frac{q D}{P}+(\bar{n}-1) q\left(1-\frac{D}{P}\right)\right) \frac{q n}{P}+\frac{1}{2}\left[2\left(\bar{n} q-(\bar{n}-1) q \frac{D}{P}\right)-D\left(t^{*}-\bar{n} \frac{q}{P}\right)\right]\left(t^{*}-\bar{n} \frac{q}{P}\right)\right\}+ \\
& +\frac{h_{f i n, f}}{T}\left[\frac{s s_{c}}{2}\left\lfloor\frac{T D}{n q} \mid \frac{n q}{D}+s s_{c} \cdot \frac{q n}{P}+s s_{c} \cdot\left(t^{*}-n \frac{q}{P}\right)\right]\right.
\end{aligned}
$$

3. Obsolescence costs (Persona et al.,2005):

$$
C_{o}^{f}=\frac{q c_{p}}{T}\left(n-n^{*}\right)+\frac{c_{p}}{T} \cdot s s_{f}
$$

4. Stock-out costs (Vollman et al., 1997, Persona et al., 2007):

$$
C_{R S}^{f}=D_{p} \cdot c_{m, f}=D_{R S, f} \cdot w \cdot(1-L S) \cdot c_{m, f}
$$

Where:

$D_{p}$ is the annual sale loss,

$w$ is the total number of shipments to be carried out in a year,

$L S$ is the Service Level defined before,

$R S$ are the number of stock-outs in a year,

$D_{R S}$ is the average value of demand unfulfilled when a stock-out occurs (the complete formula derived by normal distribution function is reported in Persona et al., 2007).

The following expression are introduced to express the quantities above:

$$
\begin{aligned}
& w=\frac{n \cdot\left\lfloor\frac{T D}{n q}\right\rfloor+\bar{n}}{T} \\
& R S=w \cdot(1-L S) \\
& D_{p}=D_{R S, f} \cdot R S=D_{R S, f} \cdot w \cdot(1-L S)
\end{aligned}
$$

5. Shipment and refilling costs: 


$$
C_{t r}^{f}=\frac{O}{T}\left(n\left\lfloor\frac{T D}{n q}\right\rfloor+n^{*}\right)
$$

Buyer's costs:

1. Holding costs, only in the buyer's plant (Persona et al, 2005):

$$
\begin{aligned}
& C_{m}^{c}=\frac{h_{\text {sto }, c}}{T}\left\{\frac{S-s s_{c}}{2}\left\lfloor\frac{T D}{n q}\right] \frac{n q}{D}+\frac{1}{2}\left(\frac{q D}{P}+(\bar{n}-1) q\left(1-\frac{D}{P}\right)\right) \frac{q \bar{n}}{P}+\frac{1}{2}\left[2\left(\left(\bar{n} q-(\bar{n}-1) q \frac{D}{P}\right)+s s_{c}\right)-D\left(t^{*}-\bar{n} \frac{q}{P}\right)\right]\left(t^{*}-\bar{n} \frac{q}{P}\right)\right\}+ \\
& +\frac{h_{s t o c, c}}{T}\left[s s_{c} \cdot\left\lfloor\frac{T D}{n q}\right\rfloor \frac{n q}{D}+s s_{c} \cdot \frac{q n}{P}\right]= \\
& =\frac{h_{\text {stoc }, c}}{T}\left\{\frac{S}{2}\left\lfloor\frac{T D}{n q} \mid \frac{n q}{D}+\frac{1}{2}\left(\frac{q D}{P}+(\bar{n}-1) q\left(1-\frac{D}{P}\right)\right) \frac{q \bar{n}}{P}+\frac{1}{2}\left[2\left(\bar{n} q-(\bar{n}-1) q \frac{D}{P}\right)-D\left(t^{*}-\bar{n} \frac{q}{P}\right)\right]\left(t^{*}-\bar{n} \frac{q}{P}\right)\right\}+\right. \\
& +\frac{h_{s t o c, c}}{T}\left[\frac{s s_{c}}{2}\left\lfloor\frac{T D}{n q}\right\rfloor \frac{n q}{D}+s s_{c} \cdot \frac{q \bar{n}}{P}+s s_{c} \cdot\left(t^{*}-n \frac{q}{P}\right)\right]
\end{aligned}
$$

2. Obsolescence costs (Persona et al, 2005):

$$
C_{o}^{c}=\frac{p}{T}\left[\frac{q D}{P}+q n^{*}-D t^{*}\right]+\frac{p}{T} s s_{c}
$$

3. Stock-out costs (Vollman et al., 1997, Persona et al., 2007):

$$
C_{R S}^{c}=D_{p} \cdot c_{m, c}=D_{R S, c} \cdot w \cdot(1-L S) \cdot c_{m, c}
$$

Where:

$$
D_{p}=D_{R S, c} \cdot R S=D_{R S, c} \cdot w \cdot(1-L S)
$$

4. Equipment hiring costs: $C_{n o l}^{c}$

This cost exists only if the buyer has to hire equipment for computerized/automatic stocking and dispensing of the items from the vendor, as is the case for PPE and small tool automatic dispensers.

The total costs are determined by the following equations:

$$
C_{t o t}(q)=C_{t o t, f}+C_{t o t, c}=C_{s}^{f}+C_{m, 1}^{f}+C_{m, 2}^{f}+C_{o}^{f}+C_{R S}^{f}+C_{t r}^{f}+C_{m}^{c}+C_{o}^{c}+C_{R S}^{c}+C_{n o l}^{c}
$$

\section{Numerical application}


In this section the model has been applied to a large number of consumable items like metallic and plastic small parts, personal protective equipment, packaging components, etc. All these items are characterized, by low price, high annual consumption, small dimensions and ease of storage, but, they reach a considerable annual monetary volume when considered cumulatively.

The data in this paragraph are relative to the production of a particular personal safety device, a protective glove for manual assembly operations, and are obtained applying the numerical values reported in table 4 to the analytical model presented in previous paragraph.

The sensitivity analysis has been conducted based on the variation of the following parameters:

- Standard deviation in market demand (in \% of the average monthly demand)

- Monthly demand (units/month)

- Maximum stock level S (units)

- Item lifetime (years)

For each parameter, the sensitivity analysis carried out by means of MatLab ${ }^{\mathrm{TM}}$ and graphically shown as follows, shows the total annual costs of the logistic system (single-vendor and single-buyer) before and after the adoption of the CS policy.

Results provided in this paragraph prove that for each parameters' variable condition the cost of the CS policy is always lower than that related to the traditional policy.

Figure 3 shows inventory level at the buyer's and vendor's warehouses, and Figure 4 shows the total costs trend as a function of the shipment quantity $q$. For this particular case study, the lowest cost obtained with the traditional policy is $2,469 € /$ year with an optimal order quantity of 2,800 units/order. The total minimum cost with the CS policy is $1,460 €$ /year with an optimal shipment quantity of 1,334 units, in accordance with the maximum inventory level $S$ ( $S=3,500$ units) imposed on both management policies. The following graphs show how the cost reduction resulting from the adoption of a CS policy can depend on the existing constraints, as reported in Figure 1. The graphs in Figure 5 represent the effect of market demand variability over the total supply chain annual costs, for the two different management strategies, reporting the ratio between the costs under CS policy and the costs under the traditional management policy, if the constraints change:

Condition 1) relaxation of the maximum inventory level S constraint (i.e. warehousing space infinite at buyer's plant, $S=$ infinite); 
Condition 2) presence of the maximum inventory level $\mathrm{S}$ constraint (i.e. warehousing space finite at buyer's plant, $S=3,500$ units);

The two graphs reported in Figure 5 show how, for the items studied, the CS policy always results in considerable savings compared to the traditional policy. The expected annual saving for the whole system (vendor and buyer) varies between $20 \%$ and $42 \%$ of the total annual management costs, depending on the constraints variation.

The graph on the left shows that total costs savings with CS policy decrease as the standard deviation in demand increases, if the constraint on the maximum inventory level at the buyer warehouse is not respected; on the contrary, if condition 2 is applied, the maximum level $\mathrm{S}$ constraint is considered. The graph on the right shows how the saving obtained with the CS policy is consistent also when the standard deviation in demand assumes high values.

Figure 6 reports total annual cost and saving analysis as a function of the item lifetime span $\mathrm{T}$ and of the maximum inventory level $\mathrm{S}$. The lower annual cost is reached when $\mathrm{S}$ equals 3,605 units, that is, about 3.6 times the average monthly consumption of the item (this result is strictly related to items that are not bulky and are easily stored, conditions which are typical of consumables), reaching an annual management cost of 1,420 $€ /$ year. The optimal shipment quantity $q$, when $S$ equals 3,605 units, is 1,501 units $(1.5$ times the average monthly demand). Total annual costs in figure 7 show an increasingly linear trend over the annual demand $\mathrm{D}$, when the vendor productivity becomes a variable function of the buyer's average monthly demand $(\mathrm{P}=40 * \mathrm{Dm})$.

\section{[PLACE HERE TABLE 4] [PLACE HERE FIGURE 3]}

Moreover figure 7 shows that as the vendor productivity increases proportionally with buyer's demand, the two curves diverge thus the adoption of the CS policy becomes more and more meaningful, resulting in increase savings whenever the demand $D$ rises. In conclusion, the numerical study demonstrates that total annual supply chain costs under CS decrease as the item lifetime span increases, whereas they increase as demand variability increases. The graphs shows that by setting a constraint $S$ in the maximum inventory level at buyer's plant (due to space limitations in buyer's warehouses), the savings reached by a CS policy increases as the variability in item demand rises. 
The results obtained in the numerical application have been applied to other simulations and the results have been confirmed for over 100 different items belonging to the following categories: steel and brass small parts, electrical and plastic fasteners, small PPE (protection gloves, earplugs, respirators, protective lenses, etc.), and large consumption tools (wrenches, screwdrivers, metal toes, etc.), all of which present an average consumptions ranging from 500 to 500,000 units per year (a real application is shown in figure 8 ).

In every case the CS management policy has shown to be preferable than the traditional one, generating an average saving ranging from $20 \%$ to $45 \%$ of the total annual costs (results of the complete analysis are summarized in table 5) .

\section{[PLACE HERE FIGURES 4, 5, 6, 7, 8]}

\section{[PLACE HERE TABLE 5]}

\section{Conclusions}

In this paper a methodological framework to support the economical and technical feasibility study related to the migration from a traditional inventory management policy to a CS policy is developed and presented. A fully developed model has been presented to support the framework and the numerical results concerning its actual application have been reported.

The model is an extension of the previous studies proposed by Braglia and Zavanella (2003), Valentini and Zavanella (2003), and Persona et al. (2005), and for the first time it considers jointly operative environments characterized by obsolescence of materials, variability in demand and finite warehouse capacity at buyer's plant.

The CS management policy results to be always preferable in comparison with the popular EOQ traditional policy (with a reorder point and fixed order quantity), producing savings ranging from $20 \%$ to $45 \%$ of the total annual management cost. Moreover, the benefit induced by the CS policy increases as the variability in demand rises, while complying with the maximum inventory level constraint $(S)$ in the buyer's warehouse.

The model can be applied to manage inventories of consumables items, characterized by low unit price, high annual consumption, small dimensions and ease of storage (i.e. metallic, electric, and plastic fasteners, small parts, PPE, small tools). 
For this kind of items, a CS management policy has been proven to be effective even in presence of variable demand, obsolescence risk and constraints in the space available in buyer's plant.

\section{Limitations and Future Research}

As previously discussed at length, the results of this study are largely in accord with our theoretical exceptions. However, like the earlier studies, the present one has its limitations that must be addressed in future researches. First of all, the inventory levels can be controlled by different control policies. Which inventory control policy should be chosen depends on the item characteristics, its use, the consumption, price, availability at the supplier, transport costs and various other aspects. The model developed in this paper aims to present a comparative evaluation of the CS policy performance compared with the EOQ policy with ROP and Safety Stocks calculation. This is justified by experiences: EOQ and ROP are the most used methods to manage inventories of consumables materials which are characterized by low unit price, high annual consumption, small dimensions and ease of storage. Future research in this field should compare the proposed CS policy with results obtained by others policies, in particular with the Fixed Order Cycle (FOC), which aims at economical reordering, by ordering all items supplied by the same supplier together at regular review times or cycle periods, and the MIN-MAX method, which refill the stock to a pre defined maximum level when quantity on stock drops below the minimum level. Moreover, the model presented in this work consider only a single vendor and single buyer system. The state of the art provided in this work underlines the necessity of future studies to address a systematic approach which considers a single-vendor and multi-buyer system in which several buyers can be managed with a CS policy by the vendor. For this reason, the authors are working on developing a new single vendor multiple buyer Consignment Stock inventory model.

\section{References}

Abdel-Malek; L., Valentini G. and L.E.; Zavanella, 2002, Managing stocks in Supply Chains: modelling and issues, in Seuring S.; Goldbach M., Cos Management in Supply Chains, Heildeberg: Physica Verlag, pp.325-335. 
Corbett C., 2001. Stochastic Inventory Systems in a Supply Chain with asymmetric information: cycle stock, safety stocks and Consignment Stock. International Journal of Operations Research, Vol.49, No.4, pp. 487-500.

Braglia M., Zavanella L., 2003. "Modelling an industrial strategy for inventory management in supply chains: the 'Consignment Stock' case". International Journal of Production Research, Volume 41, Number 16, pp. 3793-3808.

Hung, J.S,, Y.P. Fun and C.C. Li, 2003, "Inventory Management in the Consignment System", Production and Inventory Management Journal, Fourth Quarter, pp. 1-5.

Persona A., Grassi A., Catena M., 2005."Consignment stock of inventories in the presence of obsolescence". International Journal of Production Research, Volume 43, Number 23, pp. 4969-4988.

Persona A., Battini D., Manzini R., Pareschi A. 2007. Optimal safety stock levels of subassemblies and manufacturing components, International Journal of production Economics, vol. 110, pp. 147-159.

Piplani R, Viswanatan S., 2003, “ A model for evaluating supplier owned inventory strategy", International journal of production economics vol. 81-82, pp.565-571.

Srinivas Ch., Rao C.S.P, 2004, "An improved Consignment Stock Policy under Stochastic lead times for Effective Inventory Management in Supply Chain” IEEE.

Sirinivas Ch., Rao C.S.P, 2007, "Optimisation of supply chains for single-vendor multibuyer consignment stock policy under controllable lead time using genetic algorithm". Int. J. Manufacturing Research, Vol.2, No.2, 2007.

Valentini G., and Zavanella L., 2003. The Consignment Stock of inventories: industrial case and performance analysis. International Journal of Production Economics, Vol.8182, pp. 215-224.

Vollmann T.E., W.L. Berry, D.C., 1997, Whybark, Manufacturing Planning and Control System, Irwin, Business One Irwin, Homewood.

Zanoni S., Grubbstrom R.W., 2004, "A note on industrial strategy for stock management in supply chains: modelling and performance evaluation" International Journal of Production Research, vol 42, no. 20, pp.4421-4426.

Zanoni S., Ferretti I., Zavanella L., 2005, "Multi echelon spare parts inventory optimisation: a simulative study" , Proceedings 19th European Conference on Modelling and Simulation, ECMS 2005. 
Table 1. Consignment Stock policy: benefits

\begin{tabular}{|c|c|c|c|c|c|}
\hline \multirow[b]{2}{*}{ Paper } & \multirow[b]{2}{*}{ Arguments developed } & \multicolumn{4}{|c|}{ HIPOTESIS } \\
\hline & & $\begin{array}{l}\text { Market } \\
\text { Demand }\end{array}$ & $\begin{array}{l}\text { Lead } \\
\text { Times }\end{array}$ & \begin{tabular}{|c|} 
Materials Life \\
Cycle
\end{tabular} & System Type \\
\hline Corbett, 2001 & $\begin{array}{l}\text { Analysis of CS policy effects in case of information } \\
\text { asymmetries between partners involved }\end{array}$ & Stochastic & Constant & Infinite & $\begin{array}{l}\text { Single vendor- } \\
\text { single buyer }\end{array}$ \\
\hline $\begin{array}{l}\text { Valentini, Zavanella, } \\
2003\end{array}$ & $\begin{array}{l}\text { General and theoretical analysis of cost structure and } \\
\text { analytical CS model development with demand } \\
\text { variability and comparison with the Hill's model. }\end{array}$ & Stochastic & Constant & Infinite & $\begin{array}{l}\text { Single vendor- } \\
\text { single buyer }\end{array}$ \\
\hline Braglia, Zavanella, 2003 & $\begin{array}{l}\text { Analytical CS model development and comparison } \\
\text { with the Hill's model: identification of areas of } \\
\text { convenience for both. }\end{array}$ & $\begin{array}{l}\text { Deterministic } \\
\text { and stochastic }\end{array}$ & Constant & Infinite & $\begin{array}{l}\text { Single vendor- } \\
\text { single buyer }\end{array}$ \\
\hline $\begin{array}{l}\text { Piplani, Viswanathan, } \\
2003\end{array}$ & $\begin{array}{l}\text { Analytical SOI model development to evaluate its } \\
\text { performance respect to the traditional policy per } \\
\text { (EOQ and reorder level) on the whole supply chain. }\end{array}$ & Stochastic & Constant & Infinite & $\begin{array}{l}\text { Single vendor- } \\
\text { multi buyer }\end{array}$ \\
\hline $\begin{array}{l}\text { Hung et al., } \\
2003\end{array}$ & $\begin{array}{l}\text { CS industrial application case study to raw materials } \\
\text { and packaging items and introduction of an empirical } \\
\text { paremeter to define the minimum stock level quantity } \\
\text { (s). }\end{array}$ & Deterministic & Constant & Infinite & $\begin{array}{l}\text { Single vendor- } \\
\text { single buyer }\end{array}$ \\
\hline $\begin{array}{l}\text { Zanoni, Grubbstrom, } \\
2004\end{array}$ & $\begin{array}{l}\text { Generalization of Braglia and Zavanella model in } \\
\text { order to optimize delivery quantity, deliveries number } \\
\text { and postponed deliveries number. }\end{array}$ & Deterministic & Constant & Infinite & $\begin{array}{l}\text { Single vendor- } \\
\text { single buyer }\end{array}$ \\
\hline $\begin{array}{l}\text { Sirinvas, Rao, } \\
2004\end{array}$ & $\begin{array}{l}\text { CS Analytical model development in presence of } \\
\text { contracted lead time and crashing costs. }\end{array}$ & Stochastic & Variable & Infinite & $\begin{array}{l}\text { Single vendor- } \\
\text { single buyer }\end{array}$ \\
\hline $\begin{array}{l}\text { Persona, Grassi, } \\
\text { Catena, } \\
2005\end{array}$ & $\begin{array}{l}\text { CS analytical model development in case of } \\
\text { obsolescence risk and comparison with Braglia and } \\
\text { Zavanella model: guidelines for the dimensioning of } \\
\text { the new policy. }\end{array}$ & Deterministic & Constant & Finite & $\begin{array}{l}\text { Single vendor- } \\
\text { single buyer }\end{array}$ \\
\hline $\begin{array}{l}\text { Zanoni, Ferretti, } \\
\text { Zavanella, } \\
2005\end{array}$ & $\begin{array}{l}\text { CS policy application case study to spare parts items } \\
\text { and materials. }\end{array}$ & Stochastic & Variable & Infinite & $\begin{array}{l}\text { Single vendor- } \\
\text { single buyer }\end{array}$ \\
\hline $\begin{array}{l}\text { Sirinvas, Rao, } \\
2007\end{array}$ & $\begin{array}{l}\text { Single-vendor and multi-buyer model in which } \\
\text { controllable lead time and genetic algorithm are } \\
\text { considered }\end{array}$ & Stochastic & Variable & Infinite & $\begin{array}{l}\text { Single vendor- } \\
\text { multi buyer }\end{array}$ \\
\hline
\end{tabular}

Table 2. Consignment Stock literature classification 


\section{Critical factors}

Constraints:

Production capacity

Machines setup costs

Delivery costs

Re-filling costs

Annual interest rate

Holding costs

Production Lead Time daily consumption data exchange

$q$ : delivery quantity

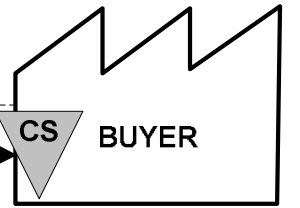

Constraints:

Annual demand

Demand variability (dev-std)

Stock-out costs

Items obsolescence risk

Annual interest rate

Holding costs

Available space for stocks

Procurement Lead Time

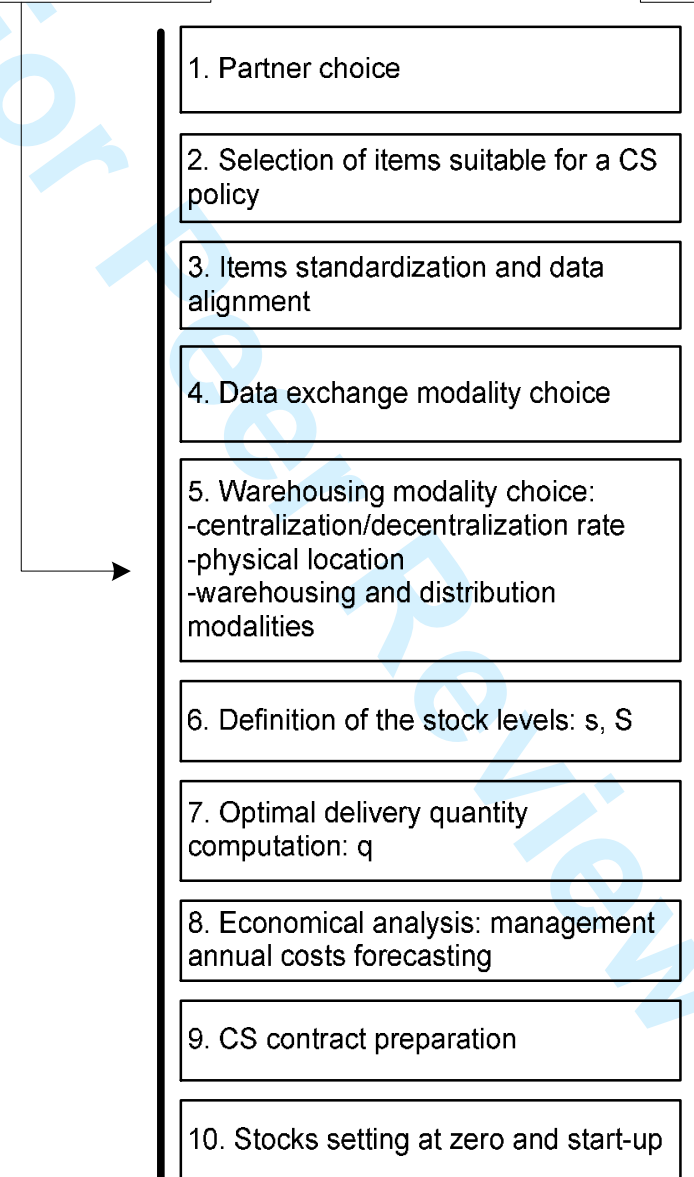

Figure 1. Methodological framework for a CS policy implementation

1) Item annual consumption rate (in pieces and monetary value)

2) Item consumption variability during the year (market demand variability)

3) Item life cycle (obsolescence risk)

4) Item standardization level

5) Supply criticalities: (variable lead times, high geographic distance vendor-buyer, etc.)

6) Item dimension and physical characteristics

7) Item stock-out costs

Table 3. Critical factors analysed in step 2 of the framework 


\begin{tabular}{|l|l|}
\hline Traditional policy & Consignment Stock policy \\
\hline$A_{1}=200 € /$ set-up; & $A_{1}=200 € /$ set-up; \\
$O=25 € /$ shipment; & $O=20 € /$ shipment; \\
$D_{m}=1000$ unit/month; & $D_{m}=1000$ unit/month; \\
$i_{f}=10 \% ;$ & $i_{f}=10 \% ;$ \\
$s_{f}=15 \% ;$ & $S_{f}=15 \% ;$ \\
$i_{c}=10 \% ;$ & $i_{c}=10 \% ;$ \\
$S_{c}=15 \% ;$ & $S_{c}=15 \% ;$ \\
$P=40000$ unit/year; & $n=3 ;$ \\
$c_{p}=0,9 € /$ unit; & $P=40000$ unit/year; \\
$p=1,2 € /$ unit; & $c_{p}=0,9 € /$ unit; \\
$c_{m, f}=150 € /$ unit lost; & $p=1,2 € /$ unit; \\
$c_{m, c}=150 € /$ unit lost; & $c_{m, f}=150 € /$ unit lost; \\
$S=3500$ unit; & $c_{m, c}=150 € /$ unit lost; \\
$T=3$ years; & $S=3500$ unit; \\
$L S=99,86 \% ;$ & $T=3$ years; \\
$k=3 ;$ & $L S=99,86 \% ;$ \\
$L T_{c}=24$ days. & $k=3 ;$ \\
& $L T_{c}=5$ days.
\end{tabular}

Table 4. Numerical application input parameters

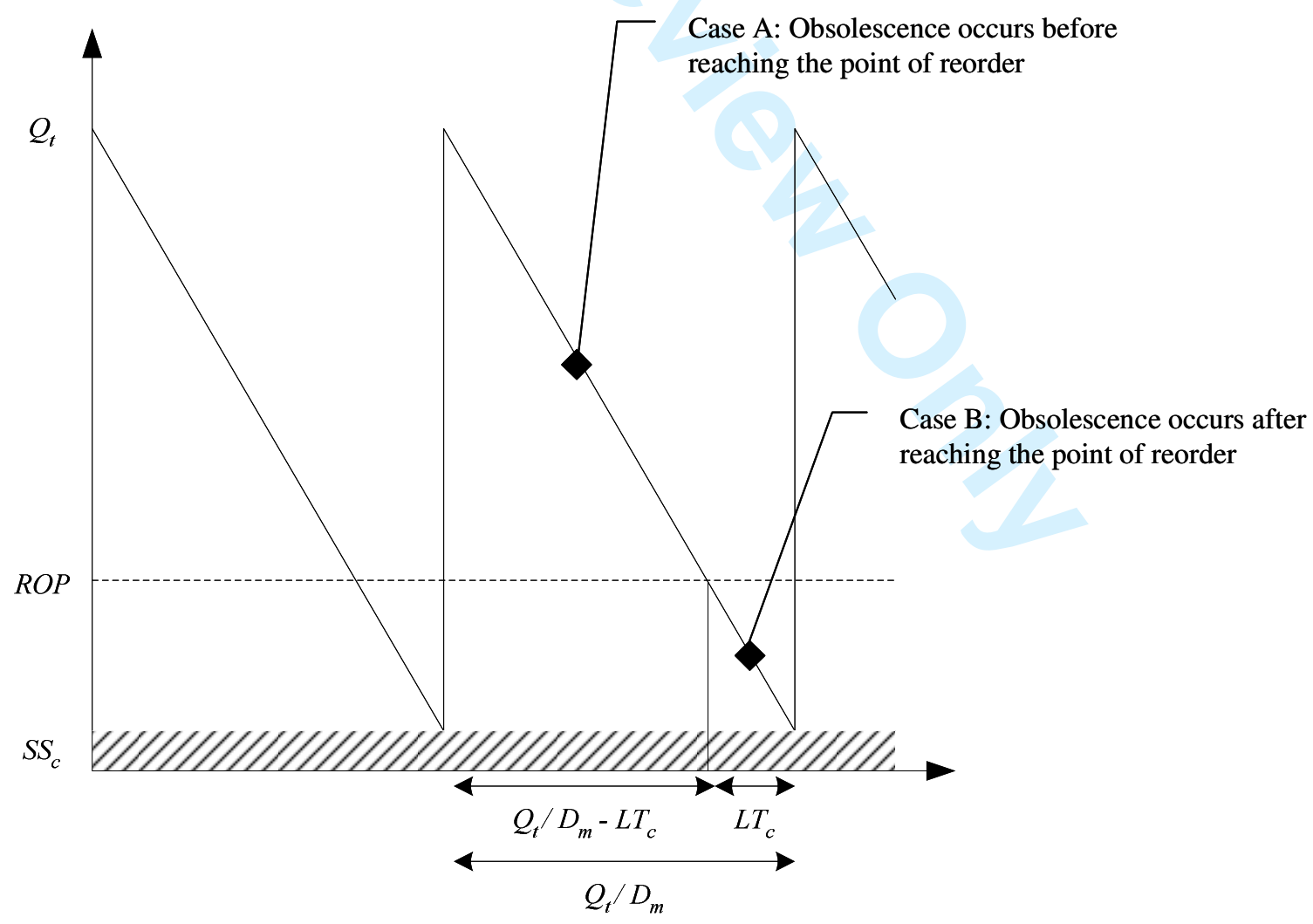

Figure 2. Deterministic obsolescence cost computation for traditional method 
a) Traditional

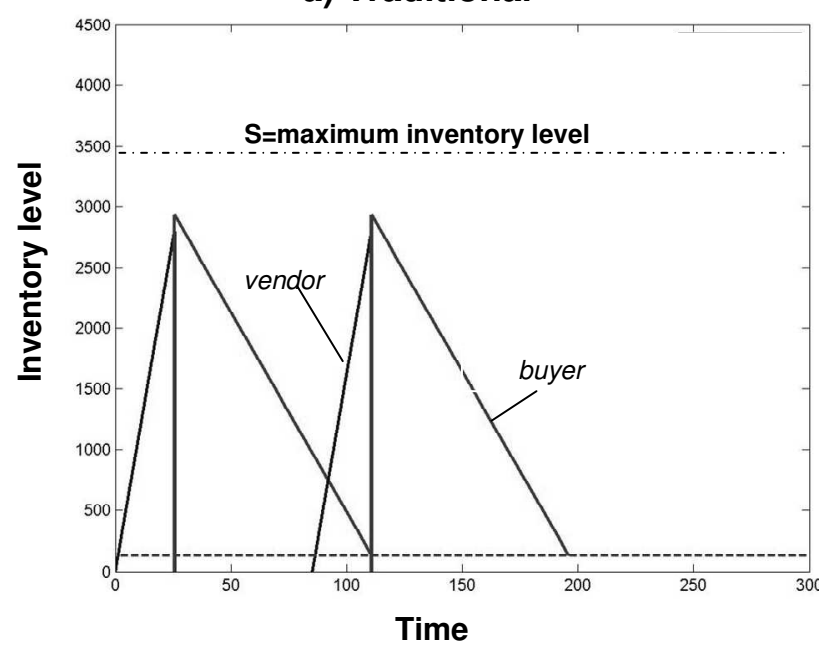

b) Consignment Stock

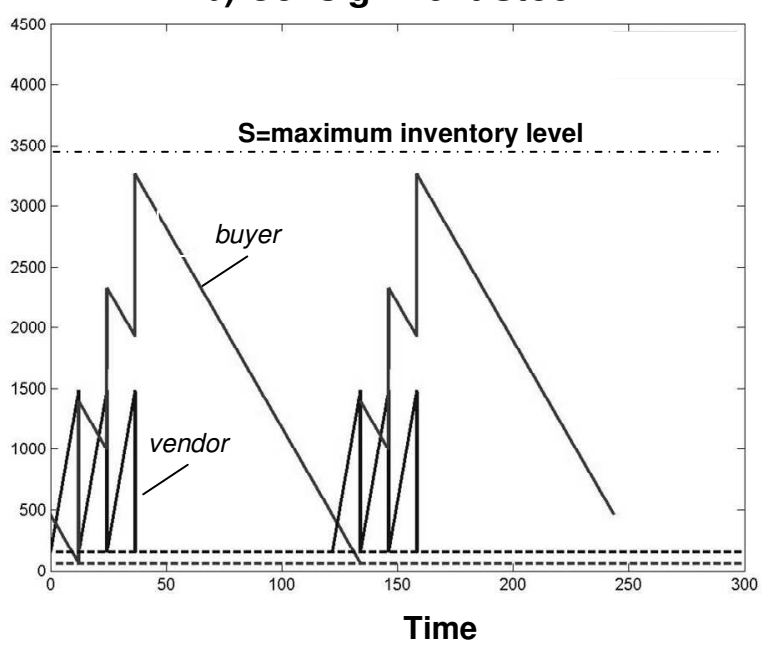

Figure 3. Vendor's and buyer's inventory level with $S=3,500$ units (buyer's maximum stock) and optimal delivery quantities (Traditional policy vs CS policy). 

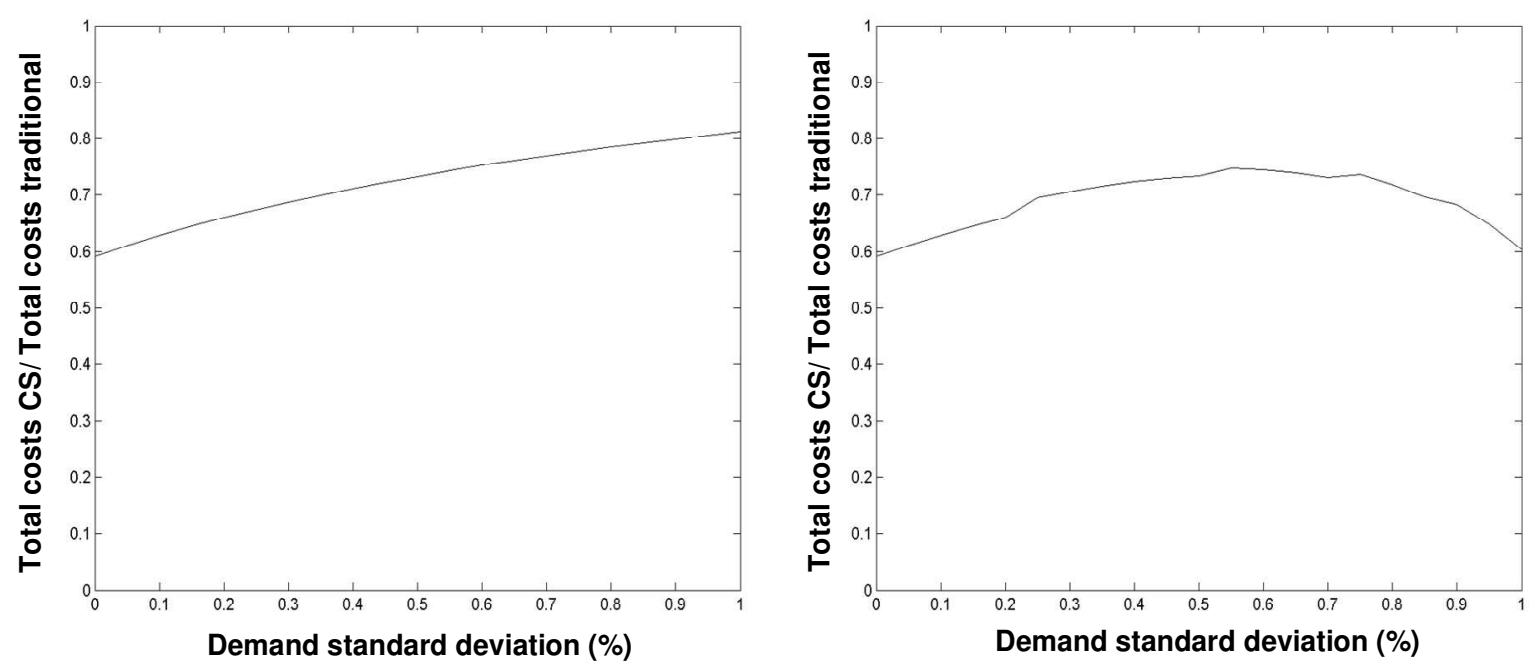

Figure 5. Total costs under CS policy as ratio to cost before CS (traditional policy) according to variation in buyer's demand standard deviation and in condition 1 (on the left) and condition 2 (on the right) . 

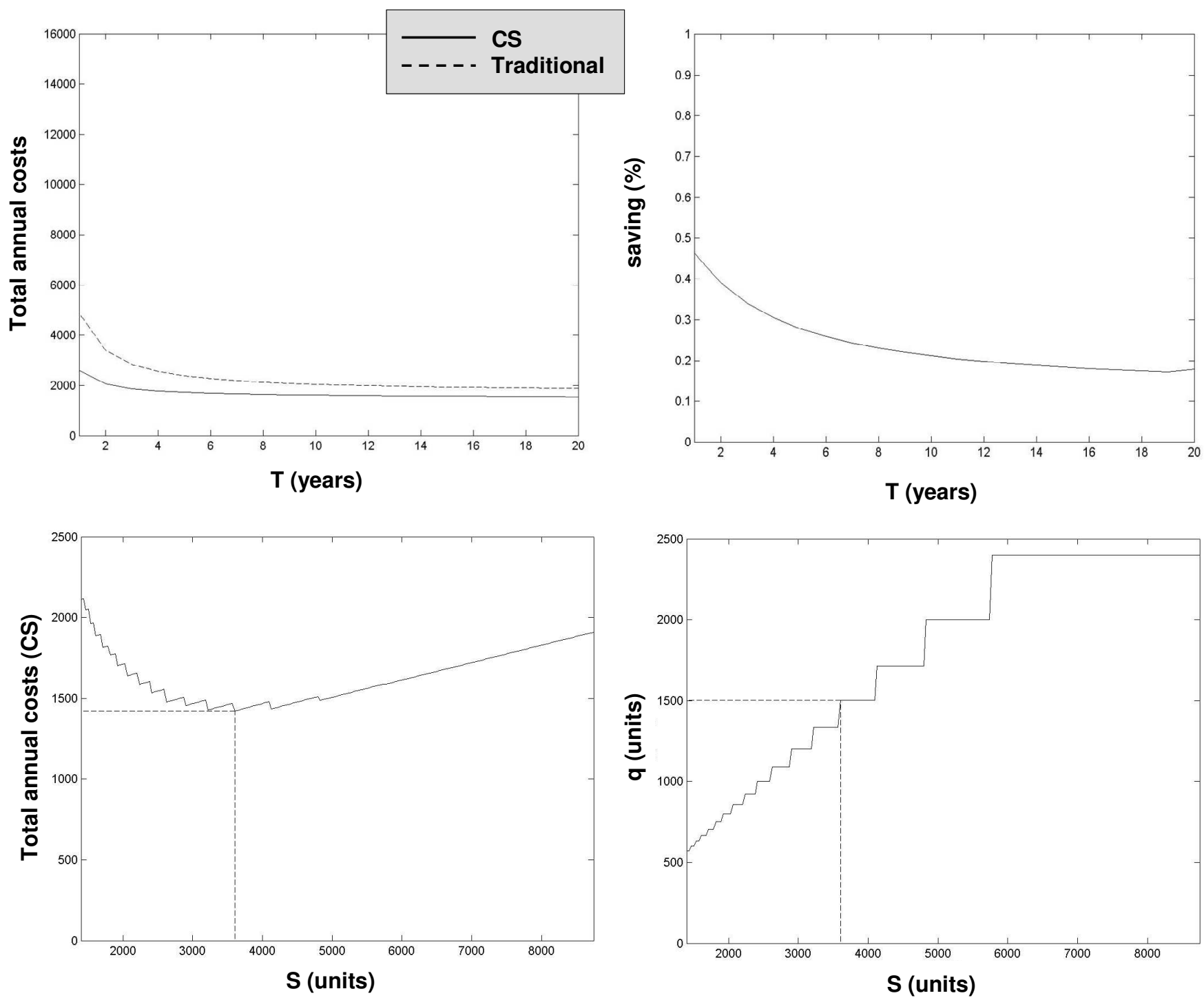

Figure 6. Total annual costs (top-left) and annual savings (top-right) according to variations in the lifetime $\mathrm{T}$ of the component (years). Total annual costs under CS (bottom-left) and optimal shipment quantity (bottom-right) according to variations in the maximum inventory level permitted $(\mathrm{S})$. 

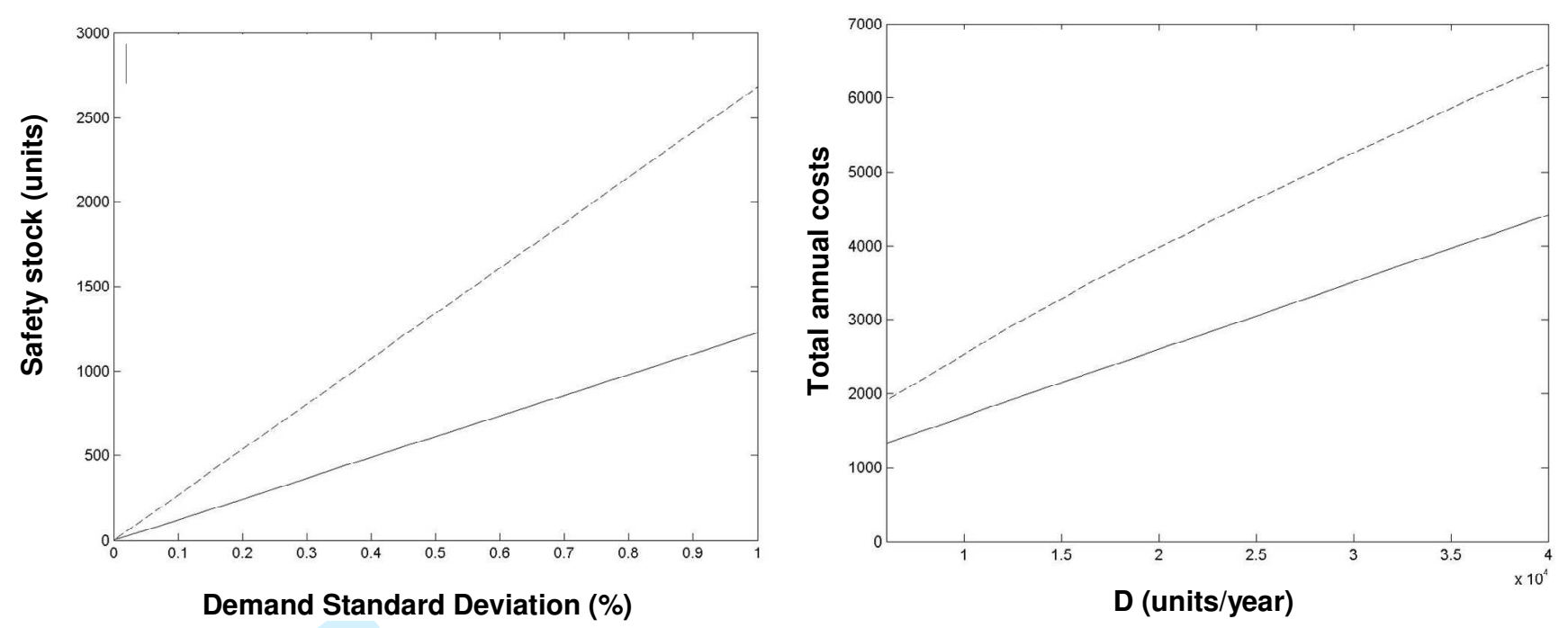

Figure 7. Safety stocks and total annual costs according to variations in demand standard deviation and in annual demand D under a traditional policy (dashed lines) and under a CS policy (continue lines).
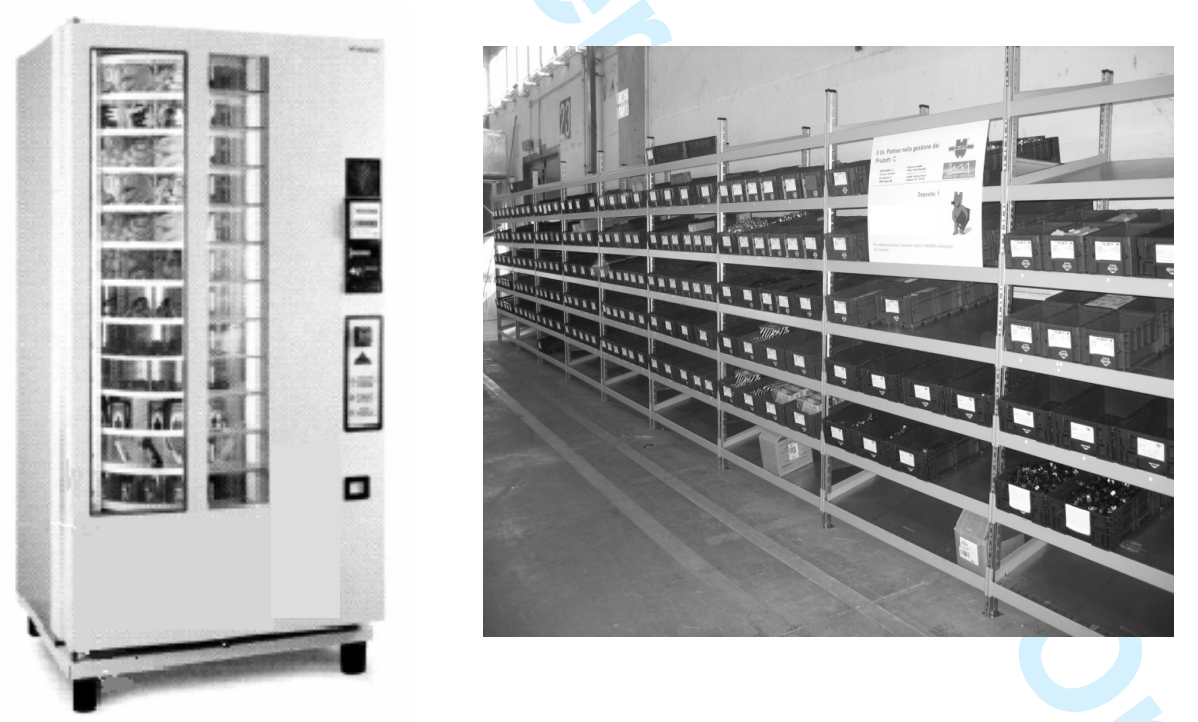

Figure 8. Consignment Stock of small PPE materials stored in automated distributors (on the left) and Consignment Stock of steel and brass fasteners stored in shelf (on the right). 


\begin{tabular}{|c|c|c|c|c|c|}
\hline \multicolumn{2}{|c|}{ ITEMS CATEGORIES } & $\begin{array}{l}\text { Annual Demand } \\
\text { (ranges expressed in } \\
\text { pieces/year) }\end{array}$ & $\begin{array}{l}\text { CS optimal shipment quantity } q \\
\text { (ranges expressed in average } \\
\text { monthly consumption) }\end{array}$ & $\begin{array}{l}S \text { level - buyer's maximum stock } \\
\text { (ranges expressed in average } \\
\text { monthly consumption) }\end{array}$ & $\begin{array}{l}\text { Annual saving with CS policy } \\
\text { (ranges expresses in \% of } \\
\text { Total Annual Cost) }\end{array}$ \\
\hline 1 & Small PPE (safety gloves, earplugs, ...) & $500-10,000$ & $0.5-1.5$ & $1.0-1.5$ & $20.5-30.5$ \\
\hline 2 & Goggles, masks, lenses & $500-10,000$ & $0.5-1.5$ & $1.0-1.5$ & $20.0-32.4$ \\
\hline 3 & Hand tools & $500-5,000$ & $1.5-3.0$ & $2.0-3.0$ & $25.5-35.8$ \\
\hline 4 & Safety helmets, caps & $500-5,000$ & $0.8-2.0$ & $1.5-2.0$ & $20.5-30.5$ \\
\hline 5 & Precious metal fasteners & $500-100,000$ & $0.5-2.5$ & $3.0-4.0$ & $20.3-29.8$ \\
\hline 6 & Glues, oils, varnishes,.. & $500-5,000$ & $3.0-4.5$ & $3.0-6.0$ & $26.7-35.4$ \\
\hline 7 & Plastic fasteners and small parts & $1,000-500,000$ & $1.0-2.0$ & $3.0-4.0$ & $34.3-45.2$ \\
\hline 8 & Electrical small parts & $1,000-500,000$ & $1.0-2.0$ & $3.0-4.0$ & $32.4-42.6$ \\
\hline 9 & Standard metal fasteners and small parts & $1,000-500,000$ & $1.0-2.0$ & $3.0-4.0$ & $31.0-43.4$ \\
\hline 10 & Metal and plastic bearings & $500-500,000$ & $2.0-4.0$ & $3.0-4.0$ & $25.2-33.2$ \\
\hline
\end{tabular}

Table 5. Results obtained during the testing phase (grouped per item category). 